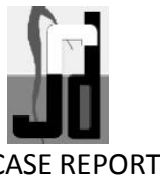

\title{
Management of the Radix Entomolaris and Paramolaris - Case Report
}

\section{Sridevi K, Jamini N.}

ABSTRACT: Mandibular molars can have an additional root located I ingually (the radix entomolaris) or buccally (the radix paramolari s). If present, an awareness and understanding ofthis unusual mot and its root $\mathrm{c}$ anal morphology can con tribute to the s outcome ofvoot cunal treatlnent. This report discusses endodontic treatment ofmandibu lar molars With Oiboth Of which in the Indian population. The prevalence, the external morphological variations and internal anatomy of the radix cntomolaris and paramolaris arc described.

Key words: Anatomical variations, endodontic treatment, mandibular molar, radix entomolaris, radix paramolaris

The prevention or healing of endodontic pathology depends on a thorough chemo-mechanical cleaning and shaping of the root canals before doing a dense root canal filling with a hermetic scal. An awareness and understanding of the presence of unusual root canal morphology can thus contribute to the successful outcome of root canal treatment.

It is known that the mandibular first molar can disnlav It is known that the mandibular first molar can display

several anatomical variations. The majority of first molors in indian population arc two rooted with two mesial and one distal canal.' • Tn most cases the mcsial root has t•wo root canals, ending in two distinct apical foramina. Sometimes, these merge together at the root tip to cnd in one foramen. The distal root typically has one kidney shaped root canal, although ifthe orifice is particularly; narrow and round, a second distal ea nal may be present.

A number of anatomical variations have been described in the mandibular first molar. F abra Campos. and Bond reported the prescnce of thrce licsial canals and Stroner noted the presence of three distal canals. Like the number of rout canals, the number of roots may also Vary, An additional third foot, first tnentioned in the literature by Carabelli is called the radix entomolaris (RE) This supernumerary root is located disto lingually in mandibular molars, mainly first molars. An additio llal root at rrmesio buccal side is called the radix working length using size $10 \mathrm{~K}$-File or case of radix entomolaris.

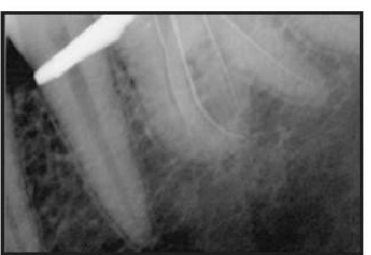

Figg 1 Determination of radiograpthie

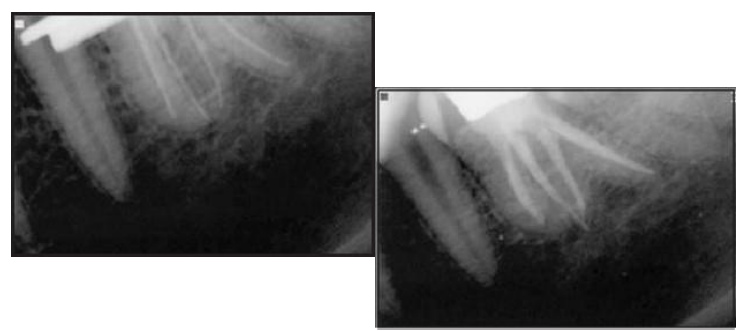

Fig 2 Guttnpercha cone fit, two separate distal roots distinguished 
41 Journal of Scientific Dentistry, ICI 2011

\section{Fig 3 Post-operative}

enromøluris

paramoluri.s

paramolaris (RP)

The identi fication and external morphology ofthese root com plexes, containing a lingual or buccal supernumerary root, are described by Carlsen and Alexandersen. Although both macrostructures are rare in the Indian population, knowledge of their occurrence and location are important. [ $\mathrm{n}$ this article two Such Cases are ented. The preval ence, external morphological variations and internal anatomy of the radix entomolaris are described

\section{CASE REPORTS}

Case I: A 28 year old female patient reported to the Department of Conservative Dentistry and Endodontics, with a complaint of pain in the ri@ht lower posterior region. She gave a history ofintennittent pain for the past one month, which had increased intensity since two days.

On examination, the right mandibular first molar displayed a restoration with tenderness on percussion. Thermal and electrical pulp testing of-the tooth el icited a

negative response. The pre-treatment radiograph showed widening of the periodontal ligament space and an additional root between the mesial and distal roots. Two radiographs with different horizontal angul ations were taken which confirmed that the additional root was located disto-lingual to the mesial root. A diagnosis of a non vital right mandibular first molar with apical perl-odontitis was made and endodontic treatment was planned.

The tooth was anaesthetized and then isolated under rubber dam. Caries was removed and cavity Was prepared using an endo access bur. One distal and two

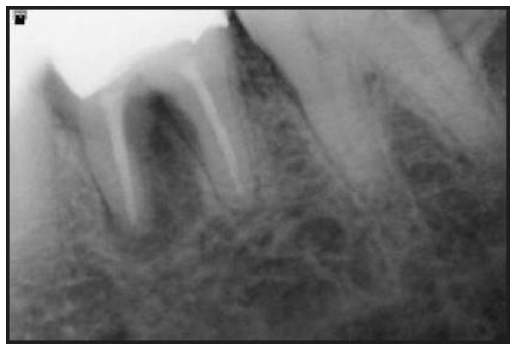

Fig 4 Pre-operative radiograph showing the missing distolingual canal

mesial canal orifices were located using an endodoutic explorer. Upon close inspection a dark line was observed between the distal canal orifice and the distolingual corner of the pu Ip chamber floor. At this corner overly ing dentin was removed and a second distal canal orifice was detected, The canal lengths were determined using radiograph and an apex locator. (Fig-I) Cleaning and shaping was pertarmed using protaper rotary instrument in crown down technique. Irrigation between cach instrument was done using $2.5 \%$ sodium hypochlorite and $17 \%$ EDTA. After the master cone selection, canals were obturated with laterally condensed gutta-percha and $\mathrm{AH}$ plus sealer. Post endodontic restoration was placed and patient was recalled for follow up and placement of full coverage crown. (Fig-2, 3)

Case 2: A 42 year old female patient reported to the department of conservative Dentistry \& Endodotics with the complaint of pain in the lower left posterior region. Patient gave a history of pain since two weeks and had a ceramic crown done by another dentist. pre OperatiVe radiograph revealed a faint outline

of an additional root apping the mesial and distal roots. Clinical, radiographic examination of left mondibular first molnr revealed that the tooth was symptomatic and endodontic retreatment was planned,

The tooth was anesthetized and isolated under rubber dam. The access cavity was prepared through the crown. On inspection of the pulp chamber floor a small hemorrhagic spot was noted buccally between the distal and the mesial orifices on the pulp chamber floor Working length determined using radiographs and an apex locater, cleaning and shaping was done using rotary protaper files. Canals were irrigated with $2.5 \%$, sodium 


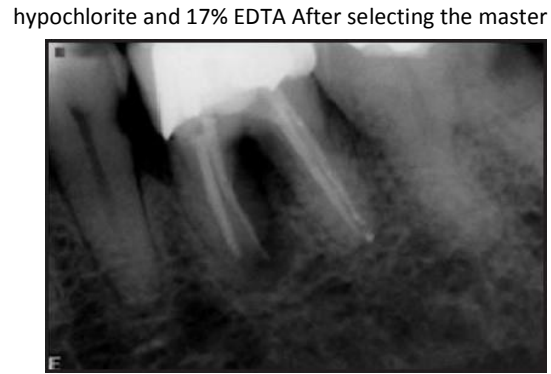

Fig S Radiograph rollouing Obtu ration of distolingual canal

$$
\text { momolaris pmramo/uris }
$$

cones, canals were obturated with gutta-percha and $\mathrm{AH}$ plus seåler using lateral condensation technique. The access cavity was restored and patient was recalled for followup. (Fig 4,5)

\section{DISCUSSION}

The presence Of a separate RE in the first mandibular molar is associated with cenain ethnic groups. In African populations, a maximum frequency of $3 \%$ is found, while in Eurasian and Indian populations the frequency is less than $5 \%$. The eti ology behind the formation of the RE is unknown and can be related to external factors during odontogenesis or to the peneterance of an atavistic gene or polygenetic system. It is hypothesized that the presence of RE adds to the stability ofmolars by providing an increased surface area of attachment to the alveolus. This anatomic structure has important clinical implications as their anatomical knowledge aids in avoiding endodontic mishaps and procedural errors.

Radix entomolaris (RE), in the pr case, characterized by the presence of an additional distolingual root was detected in the preoperative radiograph itself, This signifies the importance Of preoperative radiograph in the endodontie treatment. The 3-rooted mandibular first molar reported here had I mesial root with 2 canals and 2 distal mots with one canal each. This structure is the same as that of the other 3rooted mandibular first molars described previously. However, RE characterized hy the presence of 2 distal roots, the second one being the extra distol ingual root, is not very common amorphologic variant.

It has been reported that RCT in mandibular first molars have a significantly lower success ratc than the other teeth, One Of the reasons for non-healed root canal treatment is persistent infection caused by a missing canal and failure to remove all microorganisms and pulp remnants in the root canal system

Therefore a better ess of root anatomy is essential for improving the healing rate of root canal treatment of mandibular first molars. Apart from the awareness about the possible existence and the racial prevalence OfRE, it can be detected by thorough inspection of pretreatment radiographs, especially those taken from different angles.

Intra-oral periapieal radiographs may serve as an

important aid in identifying RE. It is suggested that the radiographs were sueeessful in over $90 \%$ of the eases while identifying additional roots. Radiographic features like double periodontal ligament images or unclear view ofdistal root/canal indicate the possibili ty ofRE.

In the present ease, all the radiographs taken during the root canal procedure were clearly suggestive of RE and prevented the need for further investigations like conebeam computed tomography and 3-dimensional reconstruction which are useful to study the morphology of RE in a noninvasive manner. Clinically, the possibilities of detec ting and managing RE can be enhanced by obtaining straight line access and modi fying typical triangular shape of access preparetion to a trapezoidal form. The values based on the mean inter orifice distance between extra distolingual canal and remaining canals, as found in a study by Tu ct al, may also serve as a useful guideline to locate and treat RE. Further, good illumination and the use of accessories like magnifying loupes, microscopes etc are also valuable in locating and managing

RE. .

\section{CONCLUSION}

Unlike in other races, radix entomolaris (RE) in mandibular first molar is not a frequent finding in the Indian population. However, Dental clinician should bc aware ofthe occuwence of RE as an anatomical variant. The detection of $\mathrm{RE}$ and its thorough cleaning, shaping and obturation would contribute significantly towards the success of primary endodontic treatment. Further, mandibulat' first molars have lower success rate following root canal treatment due to factors like missed can al Awareness about RE helps in the diagnosis and 
to betterthe overall prognosis for endodontic retreatment.

RE FERENCES

1. Barker BC, Parson KC, Mills PR, Williams GU. Anatomy of root canals. 1[1. Permanent mandibular molars. Aust Dent J1974;19:403-13.

2, Vertucci FJ, Root canal anatomy of the human permanent teethr Oral Surg Oral Mcd Oral Pathol Oral Radiol Endod $198458589-99$

Address for

correspondence:

Dr. Sridevi .K MDS

17, Vallalpari Nagar,

Akshaya Colony extension,

Mogappair
3. Thoden Van Vclzen SK, Wcssclink PR, De Clccn MJH. Fndodontologic, 2nd cd, Bohn Staflcu Van Loghum, Houtem/Diegem, 1995:142 3.

4. F abra-Campos H. Unusual root anatomy of mandibular [irst molars. J Endod 1985', 1 $1568-57$. 
5. Fabra-Catnpos $\mathrm{H}$. Three canals in the mesial root Of mandibular first permanent molars: a clinical study. J nt EndodJ 1989; 22:39-43.

6. BO nd JL. Clinical management Of middle mcsial root canals in mandibular molars. J Endod 1988; 14:312 4.

7. Stroncr WF_Mandibular -first molar with threc distal canals. Oral Surg ] 984; S7:S54 -7.

8. Carabelli G, SystcmatischesHandbueh der Zahnhcilkunde, 2nd ed. Vienna: Braumullcr und Seidel, 1844:114.

9. Bolk L. Bcmcrküngcnüber

W urzelvarlalionenammenschlichenunleren Molaren.

Zeiting fur Morphologie und Anthropologie $1915 ; 17: 605-10$.

10. Carlsen O, Alexandersen V. Radix entomolaris: identification and morphology. Scan J Dent Res 1990; 98:363 73.

11. Carl serrO, Alexandersen V. Radix paramolaris ill permanent mandibular molars: Identification and morphology. Scan Dent Res 199 1; 99:189-95.

Chennai - 600050 F mail:

drsridevi_k@yahoo.com
12. Sperber GH. Moreau JL.Study ofthe number ofrcots and canals in Senegalese first permanent mandibular

molars. Int EndodJ. 1998;31:112-6, 3

13. Tratman EK- Three-rooted lower molars in man and their racial distribution. Br Dent J. 1938;64:264-74.

14. Calberson FL, De Moor R.I, De Roose CA. The radix entomolaris and paramolaris: Clinical approach in endodontics. J Endod. 2007; 33:58-63.

15. Prabhu NT, Munshi AK. Additional distal root in permanent mandibular first molars: report of a case.

Quint Int 1995.26(8)567-69.

16. Chen YC, Lee Y Y, Pai SF, Yang SF. The morphologic

characteristics of distolingual roots ofnlandibular first molars i Taiwanese population. J Endod 2009; 35:

643-5.

17. Yew S, Chan K. A retrospective study of endodontically

treated mandibular first molars in a Chinese population.

J Ended 1993; 19: 471-73.

18. James K, Bahcall. Visual enhancement. Tn: Ingle Jl. Bakland LK. Baumgartner JC, editors. Ingle's Endodontics.6th ed. Hamilton: BC Decker Inc; 2008 870-76

How to cite this article:

Sridevi K, Jamini N, A Clinical Approach to diagnosis and management of the Radix Entomolaris and Paramolaris, Journal of Scientific Dentistry 2011;1(1):41

Source of Support: Nil, Conflict ofInterest: None declared 